Scaffolding argumentation in intact class: Integrating technology and pedagogy

\author{
Jingyan $\mathrm{Lu}^{1 *}$ Zhidong Zhang ${ }^{2}$ \\ ${ }^{1}$ Faculty of Education, The University of Hong Kong, Pokfulam road, Hong Kong, \\ ${ }^{2}$ The College of Education, The University of Texas at Brownsville, Texas, Texas,78520, USA, \\ jingyan@hku.hk,zhidong.zhang@utb.edu
}

* Corresponding author:

Jingyan Lu

Division of Information and Technology

Faculty of Education

The University of Hong Kong

Pokfulam Road, Hong Kong

Tel: 852-2241-5450

Fax: 852-2547-1924

jingyan@hkucc.hku.hk 


\title{
Scaffolding argumentation in intact class: Integrating technology and pedagogy
}

\begin{abstract}
This paper reports on the use of a set of online tools to scaffold the argumentation skills of students enrolled in Liberal Study. The tools, collectively known as OASIS, were designed to support the online reading, writing, and evaluating activities of students engaged in fulfilling the learning objectives of the course. OASIS was designed to be integrated into the teaching and learning activities of the course. Two classes of students used the tools over an entire school year. We examined how the students used the tools to read and write arguments and how this affected their argumentation skills. The data collected included the number and types of tags students assigned to text passages and the quality of the arguments they produced in their written essays. Students’ argumentation skills were found to be related to the number of tags they defined. OASIS was found to be effective in scaffolding students’ argumentation skills. However, limitations were identified during task design, especially the design of collaborative peer evaluation tasks.
\end{abstract}

Keywords: argumentation skills, argumentation tools, liberal study, critical reading; argument structure 


\section{Introduction}

The design of online tools to facilitate teaching and learning has attracted the attention of educators and researchers. Tools have been designed to scaffold learning in a number of areas including critical reading (Lu \& Deng, 2012), writing (Neuwirth \& Wojahn, 1996; Yang, 2010), reasoning (Toth, Suthers, \& Lesgold, 2002), argumentation (Clark, Stegmann, Weinberger, Menekse, \& Erkens, 2007), and problem solving (Friedman \& Deek, 2002). Argumentation involves the exercise of both thinking skills and discourse skill. Further, given that argumentation pervades both academic life and everyday life (Kuhn, 2005; 2009),development of it ought to be an important educational goal (Mercer, 2009). Unfortunately, research has shown that students at all academic levels have difficulty developing argumentation skills (Knudson, 1991); even graduating high-school students have difficulty producing, understanding and evaluating arguments (National Assessment of Educational Progress, 1998; National Science Board, 2006).

Although, argumentation has received little attention in Hong Kong (HK), a recent report by the Hong Kong Examination and Assessment Authority (HKEAA) on the performance of students enrolled in Liberal Study (LS), a new core subject in HK secondary schools, states that although students in general "showed good understanding and knowledge in different topics”, they were "poor in analyzing information from different perspectives and thus were not able to compare and argue with different evidence” (Hong Kong Exxamination and Assessment Authority, 2012). The report went on to suggest that since the argumentation skills of students were weak, schools should take steps to help students strengthen them. Two questions that arise here are what skills should schools teach and how should they teach them? That is what skills constitute good argumentation skills and how can schools integrate them into the regular curriculum? Generally, learning and technology design should take into 
consideration the needs, goals, activities, and educational contexts of learners (Andriessen \& Schwarz, 2009). The learning contexts that are embedded in educational systems and are represented by teachers, should direct the design of learning environments as they strongly influence eagerness of learners to argue (Quintana et al, 2005).

This study sought to support the development of argumentation skills by embedding them in basic learning activities of students in Liberal Study. It explored the use of OASIS, a set of argumentation tools, to scaffold the reading, writing, and evaluation of arguments by LS students. More specifically, it focused on how OASIS supported students' reading activities and how this related to the quality of their written arguments.

\section{Theoretical background}

\subsection{Argumentation skills}

Although, argumentation skills and arguments can vary across subject areas e.g., psychology (Muller Mirza, Perret-Clermont, Tartas, \& Iannaccone, 2009; Nussbaum \& Sinatra, 2003), logic (Oaksford, Chater, \& Hahn, 2008), philosophy (Walton, 1996), pragmatics (Van Eemeren \& Grootendorst, 1994), and education (Kuhn, 2005), they also have features in common. For instance, argumentation involves both thinking skills and discourse skills (Kuhn, 2005; Muller Mirza, et al., 2009) while arguments can be evaluated with respect of their structure and the quality of rebuttals (Erduran, 2007; Kuhn, 1991; Toulmin, 1958). Further, arguments can vary according to the expertise of individual arguers (Goldstein, Crowell, \& Kuhn, 2009).

The most influential model of argument structure is Toulmin’s (1958) six-component model: claims, data, warrants, backing, qualifiers, and rebuttals. Educational researchers have used Toulmin's model to investigate arguments in a number of subject areas (Chang \& Chiu, 2008; Osborne, Erduran, \& Simon, 2004). According to Toulmin, the quality of arguments 
should not be judged on the basis of individual components, but rather on their overall structure (Chinn \& Anderson, 1998; Chinn, O'Donnell, \& Jinks, 2000; Clark, Sampson, Weinberger, \& Erkens, 2007; Means \& Voss, 1996). Thus, Means and Voss (1996) proposed three levels of argument structure: skeletal, enhanced, and elaborated. A skeletal argument has one claim supported by one reason. An enhanced argument has of one claim supported by one reason plus two or more qualifiers and an elaborated argument has two or more claims supported by two or more reasons plus two or more qualifiers. Chinn et al $(1998,2000)$ graded argument structures from low to high. Low level arguments have simple reasons supporting claims while high level arguments are composed of complex networks of multiple sub-arguments and rebuttals. Similarly, Schwarz et al (Schwarz, Neuman, Gil, \& Ilya, 2003) arranged argument structures into a hierarchy ranging from simple claims to compound arguments. Thus, high level argument structures involve multiple perspectives that are supported by rich evidence. Salder and Fowler (2006) developed an five point rubric to assess the quality of argument by simplifying Toulmin's model to justifications for claims proposed by high school students, college non-science major students and college science major students. And finally Venville and Dawson (2010) evaluated the structure of argument on socio-scientific issues developed by high school students based on the presence of components of Toulmin's model.

Rebuttals involve "exceptional conditions capable of defeating or rebutting the warranted conclusion” (Toulmin, 1958, p. 94). They challenge the grounds of claims and indicate the quality of arguments as “oppositional episodes without rebuttals have the potential to continue forever with no change of mind or evaluation of the quality of the substance of an argument” (Erduran, Simon, \& Osborne, 2004, p. 927). Research indicates that as rebuttals become more clearly identifiable the quality of arguments improve (Clark, D., et al., 2007; Erduran, et al., 2004). Rebuttals indicate the quality of arguments in that they challenge 
participants to evaluate the validity and strengths of arguments (Erduran, 2007). Further, rebuttals are evidence of the development of cognitive argumentation skills (Kuhn, 1991).

Although, argumentation structure and rebuttals are good indicators of argumentation skills, it is difficult to directly connect them to the development of class argumentation activities. Thus, it is important to understand the processes and activities through which students develop argumentation skills in the class.

\subsection{Argumentation in class: Reading, writing, and evaluating arguments}

Given that a great deal of the argumentation that takes place in the classroom, occurs in face-to-face and online discussions, peer evaluation, and in written essays, there is an increasing recognition of the need to develop learning activities that provide students with authentic tasks aimed at fostering the development of effective argumentation skills (Means \& Voss, 1996). One natural way of integrating argumentation skills into instruction is to develop activities that involve reading, writing, and evaluating arguments. Although, it is relatively common for students to engage in oral argumentation with peers in school playgroups or with family members at home, it is difficult to engage them in high quality classroom debates (Andriessen, 2009; Garcia-Mila \& Andersen, 2007) and it is even more difficult to get them to focus on writing high quality arguments. Children acquire oral argumentation skills in non-academic situations at home and at school. However, acquiring written argumentation skills involves more than simply learning to engage in oral debates. Rather, the problems facing children regarding the acquisition of argumentation skills involve not only the development of basic literacy skills, but also the ability to examine, compare and select diverse facts, ideas, arguments and opinions from a variety written sources, and to anticipate and rebut objections or disagreements (Muller Mirza, et al., 2009). 
Thus, teaching students to write arguments poses pedagogical challenges to teachers (Kelly, Regev, \& Prothero, 2007). Helping students identify the key elements of arguments during reading might help. Students must be able to analyze the arguments they read in order to write effective arguments. They must be able to interpret written sources, extract and examine ideas, organize and compare perspectives and opinions, and select and analyze information to be used in writing arguments. However, the processes by which students "transform source texts into well-reasoned claims" addressing specific issues (Higgins, 1993, p. 73) have received little attention compared to oral and written argumentation. Thus, we need effective ways of helping students learn how to read-to-argue (Higgins, 1993, author, 2012).

Students are often involved in peer assessment during which they evaluated each other's written argument. Evaluating the arguments of others (Kuhn \& Goh, 2005) involves: 1) identifying key elements of arguments and 2) judging their quality, e.g., are they reasonable, do they provide sufficient evidence. Students are weak in evaluating the epistemological characteristics of arguments or what they understand arguments to mean (Goldstein, et al., 2009). This suggests that students focus on the content of arguments as opposed to their structure and reasoning because they judge the arguments of others based on their own preferences and ignore the epistemic strengths or weaknesses of the arguments themselves (Kuhn, 2005). Larson, Britt, and Kurby (2009) found that students improved their ability to evaluate arguments with a little training in evaluating them and immediate feedback.

\subsection{Argumentation tools}

Argumentation tools such as Belvedere (Suthers et al., 2001), Digalo (Schwarz \& Glassner, 2007), Convince Me (Ranney \& Schank, 1998), Sense Maker (Bell, 2000), CASSIS (Kobbe et al., 2007), and Knowledge Forum (Scardamalia, 2004), have been designed and 
developed to provide learners with external argumentation frames to scaffold their efforts to construct arguments. External argumentation frames can support students construct effective arguments by encouraging them to engage in explicit exploration and negotiation.

Argumentation frames can be linear or nonlinear. Linear frames present arguments as lists (van Drie, van Boxtel, Jaspers, \& Kanselaar, 2005) and threaded discussions (Scardamalia, 2004; Stegmann, Weinberger, \& Fischer, 2007) while nonlinear frames present arguments as graphs, diagrams (Nussbaum, Winsor, Aqui, \& Poliquin, 2007; van Amelsvoort, Andriessen, \& Kanselaar, 2007) and matrices (van Drie, et al., 2005). Linear and nonlinear frames scaffold different kinds of argumentation skills and thus scaffold student argumentation in different ways. Linear frames use lists and threaded discussions to scaffold students in constructing arguments in the context of online and face-to-face discourse. For example, Knowledge Forum provides sentence openers such as "my theory”, "my evidence”, and "I don't agree” to scaffold collaborative argument construction. This form of representation is appropriate for argument topics that cannot be reduced to nodes and connections because they require rich linguistic elaboration. The graphs and diagrams of nonlinear frames can scaffold the construction arguments based on abstract ideas (Suthers, 2003). For example, Belvedere supports scientific reasoning by creating different graphical languages to express the steps of formulating hypotheses, gathering data, weighing information, and creating different symbol systems for representing logical and rhetorical relationships within arguments (Suthers, 2003). CASSIS provides scripts in dialogue box that prompt students to supply the claims, grounds, and qualifications that can later be transformed into prespecified textual structured argument they are constructing (Kobbe, et al., 2007). Visual representations of arguments can simplify complex logical relationship among their different components. Most online argumentation tools focus on scientific arguments as finished products rather than on scaffolding learners engaged in the process of reading and constructing arguments. 
For instance, in order to write good arguments, students also need to be able to read critically or argumentatively. As more and more reading materials become available online, the need for tools to help students read critically increases. Currently, there are a number of annotation tools that support students in accessing, managing, sharing, and interacting with digital texts (Wolfe, 2002). The tools, such as WebNotes ${ }^{1}$, SharedCopy ${ }^{2,}$ Marginalia $^{3}$, allow users to highlight, tag, make notes online, save the URL, annotations, and taggings in private folders, organize annotated information, and share it with others via email or social networks. However, these tools have limitations. For instance they separate texts from annotations (Nokelainen, Miettinen, Kurhila, Floréen, \& Tirri, 2005) or they focus too much on the technical design (e.g.,Glover, Xu, \& Hardaker, 2007; Rau, Chen, \& Chin, 2004). Further, there is little research on the pedagogical design, implementation, and impact of online annotation tools including tools specifically designed to scaffold argumentation skills. In our recent work, we have explored the use of Diigo (Digest of Internet Information, Groups and Other stuff) as an online annotation tool to help students engage in reading arguments critically (Authors, 2012). Our findings revealed that Diigo supports the constructive processing of arguments by providing highlighting, tagging, and annotating tools that students can use in identifying, analyzing and commenting on written arguments. However, given Diigo’s limitations, our findings have not been able to reveal how students' online reading activities are related to the quality of their written arguments. Consequently, in this study we sought to design argumentation tools to scaffold students so as to explore how the ways in which they read arguments affected how they write arguments. The design of the study is described in the next section.

1. http://www.webnotes.net/

2. http://sharedcopy.com/

3. http://webmarginalia.net/ 


\section{Context}

This study focuses on the argumentation skills of students enrolled in Liberal Study (LS) a core course that was introduced into HK schools in 2008. LS covers six areas: Personal Development and Interpersonal Relationships, Hong Kong Today, Modern China, Globalization, Public Health, and Energy Technology and the Environment. According to the Education and Manpower Bureau, (Education and Manpower Bureau, 2007) LS 'provides students with opportunities to explore issues relevant to the human condition in a wide range of contexts and enables them to understand the contemporary world and its pluralistic nature'. Thus, LS modules were designed to help students improve their ability to read critically, search for and organize information, and collaborate more effectively with their peers.

The authors have been working with HK schools for more than 5 years in a series school partnership projects that have involved using web 2.0 tools to help students engage in collaborative learning (Authors, 2011) and peer assessment (Authors, 2012), and using annotation tools to facilitate critical reading (Authors, 2012). We first introduced Diigo, another set of online tools that we had designed to address practical and pedagogical issues raised by teachers and theoretical issues arising from current research on argumentation. The present study is part of our continuing effort to use annotation tools to facilitate argumentative reading (Author, 2012). Based on limitations we observed in how students used Diigo’s annotation tools, we designed OASIS to address limitations encountered in our earlier studies, In particular we observed limitations involved in the use of tools for tagging. It was first introduced to teachers in the workshops to all teachers from our partnership schools to get their comments and feedback tools design and usability. It was then revised till most comments were addressed and then ready to be introduced to students. Three LS modules were selected to use OASIS in the regular teaching and learning and the schedules 
were set to avoid with major schools events, such as exam so that researchers can get into schools without putting much pressure on students to use the new technology since it might take time to learn the new thing. The topics of the three modules were "Government Policy Address”, “Gene Screening” and “Moral and National Education”. The detailed task design for each module will be described in the method section.

\section{Research questions}

This study adopted an exploratory method to examine how students used OASIS to read, write, and evaluate arguments. Our aim was to explore whether using OASIS to support their readings activities affected their ability to write arguments. If OASIS is helpful which feature is most conductive? We focus on the following two questions:

- How do students read, write, and evaluate arguments with OASIS?

- Did using OASIS to read articles (Tasks 1 and 2) affect the argumentation skills of students in writing essays and why?

\section{Methodology}

\subsection{Participants}

Eighty three grade 10 students from two classes in the same public high school participated in the study. The school was chosen as a convenience sample from among the schools participating in a university-school partnership project involving the use of online platforms in teaching and assessing Liberal Study courses. The students in the two classes received the same instruction, engaged in the same types of learning activities and were assess according to the same standards. Both teachers had more than 10 years teaching experience and were involved in the university-school partnership programme. Both were involved in the design of OASIS and had worked together on lessons plans for the course. 


\subsection{Research design}

This case study involved the design of both learning tasks and tools. As intact classes were selected, there was no intention to interfere with the regular curriculum and practice. The teachers and the researchers worked closely on planning the learning tasks and on designing the tools for scaffolding students in their efforts to carry them out. The teachers and several students were interviewed on how effective OASIS was in supporting the development of argumentation skills.

\subsection{Task design}

Each module comprised 4 tasks all of which called for the exercise of argumentation skills. OASIS tools were designed to scaffold the argumentation skills that students needed to use to carry out the various learning tasks. In Task 1, students used OASIS to read and analyze articles that had been assigned by their teacher; in Task 2, they used OASIS to read and analyze articles that they had selected; in Task 3, they analyzed the information that they had collected in Tasks 1 and 2 and summarized in OASIS to write an argument essay; and in Task 4, they used OASIS to evaluate the essays of peers. Students used OASIS for all three modules. However, since students needed to become familiar with OASIS during the first module, they didn't use it for Task 4. Students used OASIS for all 4 tasks in the second and third modules.

\subsection{Tools design}

OASIS consists of a set of online tools that were designed to provide students with support in reading, writing, and evaluating arguments. The tools scaffolded students by enabling them: 1) to highlight and tag passages in written texts; 2) to organize and manage the passages that they had highlighted and tagged for later use in writing their own argument 
essays; and 3) to highlight and tag passages in the written arguments of their peers. The tools for highlighting and tagging passages scaffold the process of reading-to-argue by prompting students to highlight and tag passages with purpose in articles.

Students could choose two types of tags: Task-tags and My-tags. Task-tags are tags that are defined by teachers and My-tags are tags that are defined by students (See Figure 1). Task-tags include: position, argument, pro-claim, con-claim, and evidence. We hope that the Task-tags scaffold students in practicing their argumentative skills in a designed framework. That is, we hope that the students were able to conduct argumentative analysis by using the analysis structured designed and designated by teachers. We also think that students may have their own ways of understanding arguments and want to label them based on their own understanding. The My-tags are created for that purpose.

Thus, selecting, highlighting and tagging passages helped students construct arguments by scaffolding their efforts to understand key ideas in the articles and to identify and analyze different perspectives and supporting evidence. OASIS also supports students in evaluating arguments. In task 4 students were required to read the written arguments of their peers, identify the parts of their arguments and then judge the quality of their arguments. For the evaluation task students could use Evaluation-tags that were created by their teachers or they could create their own Evaluation-tags as well. In the following section, we discuss two key features of OASIS and its design rational.

Insert Figure 1 about here

\subsubsection{The highlighting tool: Reading to argue}

The highlighting tool scaffolded the efforts of students to read articles critically by visually marking passages that were significant to the arguments they contained. The groups 
of passages that students highlighted helped to draw their attention to significant features of arguments in the articles and to make the passages available for later reference when it came time for students to extract, organize and re-structure argument from the articles in order to write their own essays (O'Hara \& Sellen, 1997).

\subsubsection{The tagging tool: Understanding argumentation}

A basic idea guiding the design of the highlighting tool was that highlighting should be a purposeful and meaningful activity. When students highlight passages they should aim at achieving in higher levels of cognitive engagement. They should not simple engage in coloring passages of written texts. To achieve this, the highlighting tool was linked to the tagging tool. The tags that students attached to the passages they highlighted can be seen as external representations of their efforts to make sense of what they were reading and efforts at organizing their emerging understanding of what they were reading (Hong, Chi, Budiu, Pirolli, \& Nelson, 2008). Thus, when students highlight a passage, they are prompted to choose from a list of Task-tags that their teachers have defined or from as list of My-tags that they have defined (See Figure 1).

\subsection{Data sources}

Data on the reading and writing activities of students for the third module, "National and Moral Education” (later NE) were selected for further analysis. Three types of data were collected: 1) online annotation data, including data from articles selected by the teacher (Task 1), articles selected by students (Task 2) articles, and essays written by students (Task 4), 2) analyses of argument essays by researchers, and 3) interview data.

\subsubsection{Online behavior: Reading-to-argue and evaluating argumentation}


Online annotation data consisted of the total numbers of highlighted and tagged passages for Tasks 1, 2, and 4. Since all highlighted passages were tagged and all tagged passages were highlighted, only tags were counted. The same set of Task-tags were used in Tasks 1 and 2. They included: Position, Argument, Pro-, Con-, and Evidence. Pro- and Con-tags were collapsed for analysis as they represented the same argument idea. Different tags were defined for evaluating the arguments of peers in Task 4. These tags included: "Insufficient explanation”, “Unreasonable evidence/explanation”, “Reasonable evidence/explanation” and "Illogical”. Tags that were defined to evaluate the written arguments of peers were collapsed for analysis as they represent the same idea. Students could also create their own My-tags for both reading tasks (Tasks 1 and 2) and the evaluating task (Task 4) when they felt that none of the teacher defined Task-tags fit a passage that they had highlighted. Total numbers of My-tags were summed for each task.

\subsubsection{Argumentation skills measured in essay writing}

Students' written essays were analyzed in terms of complexity of argument structure and level of rebuttal. The analytical perspectives, complexity of argument structure and level of rebuttals, are rooted in Toulmin's (1958) argumentation model but were further developed both bottom up and top down. Coding for quality of argument structure was adapted from the work of Chinn and Anderson (1998) and Clark et. al. (2007) (Table 1).

Insert Table 1 about here

\subsection{Data analysis}

Descriptive analysis and qualitative analysis were used to characterize the argumentation activities and skills of students using OASIS. Multiple regression analysis was used to 
examine the reading activities with OASIS and writing quality controlled by students' LS exam performance from previous year. Reading activity variables with significant correlations with LS exam scores were entered into the regression model.

\section{Results}

6.1 How do students read, write, and evaluate argumentation with OASIS?

Table 2 summarizes the online annotating activities of students with OASIS, writing performance across three dimensions of argumentation, and the exam scores collected before the study. Students showed mediocre performance with respect to argument structure (M= 3.65) but they did very little rebuttal $(M=.58)$. With respect to tagging, students tended to tag more Evidence $(M=7.16)$, Pros $(M=5.86)$ or Cons $(M=6.03)$, and to tag fewer positions $(\mathrm{M}=4)$ and arguments $(\mathrm{M}=2.22)$. They created an average of 3 My-tags while reading. They did very little tagging while evaluating the essays of peers $(M=1.21)$ and they use very few My-tags ( $M=1.22)$.

Insert table 2 about here

Table 3 provides the correlations of major variables. Writing quality was significantly correlated with three reading activities: number of Evidence tags $(r=.248, p<.05)$, number of Position tags $(r=.262, \mathrm{p}<.05)$, and number of My-tags $(r=.281, \mathrm{p}<.05)$.

Insert table 3 about here

6.2 Did using OASIS to read articles (Tasks 1 and 2) affect the argumentation skills of students in writing essays and why? 
Only quality of argument structure was taken as a dependent variable in the regression model since there were too few rebuttals to include level of rebuttal in the regression analysis. The multiple R squared correlation coefficient was .17 indicating that the reading activities of students accounted for about $17 \%$ of quality of argument structure variance. The control variable, exam scores from the previous semester, was a marginally significant predictor ( $\Delta$ $\mathrm{R} 2=0.054, \mathrm{p}=0.058)$. Adding the online reading activities produced significant change in variance to the model $(\Delta \mathrm{R} 2=11.7, \mathrm{p}<.05)$. The number of My-tags was the only significant predictor of the quality of argument structure $(\mathrm{t}=2.2, \mathrm{p}<.05)($ Table 4$)$. Although, significantly correlated with argument structure, the number of Evidence-tags and Position-tags were not significant predictors.

Insert table 4 about here

To understand why the number of My-tags was significant to argument writing quality, we focused on the types of My-tags that students generated. Examples of My-tags were: example, supporting evidence, opposing evidence, explanation, suggestion, rebuttal, reason, consequence, and stakeholders.

Both teachers were interviewed with respect to their perceptions of using OASIS to support students learning. The teachers acknowledged the importance of OASIS in helping students identify, differentiate, and organize important information while reading critically and that such behavior could be developed into habits when they used OASIS in the future. For example, one teacher said that "summarizing reading material in excel will help students organize the argument elements, but the challenge is how they will analyze and integrate the information into their written arguments”. Besides, the teachers were more excited about the use of OASIS to scaffold students in evaluating the work of peers. 
Students were asked their experience of using OASIS. Students mentioned when reading materials on the paper, they use highlighter to mark down the information they think important, and put them together for later reference writing. When reading moved to online, it is hard to them to mark down the important information. So they have to go page by page online when writing. OASIS helped them transfer their behavior of reading paper materials to reading online. They are not only able to highlight, but also label them with different argument tags. What's more is that they can summarize and organize different online materials and analyze them when writing. Students also created their own tags when teacher-defined tags were found to be inadequate. Students said that they created tags to help them identify important ideas and to understand and analyze articles. It was found that students who created their own tags read arguments better and wrote better arguments.

\section{Discussion}

Argumentation is highly relevant and important to classroom learning, both in the sciences and the humanities. Although, it has been well recognized that students at all levels lack argumentations skills, not much has been done to address this problem in authentic classroom environments. This study took an exploratory approach based on the idea that argumentation skills should be recognized and explicitly modeled for learning tasks in which students are required to read, write, and evaluate arguments. It introduced a set of online argumentation tools to support students in their efforts to read, write, and evaluate arguments and it examined whether such learning activities affected their argumentation skills.

\subsection{Students’ online argumentation activities and skills}

The fact that students used many teacher defined Task-tags in the reading Tasks 1 and 2 but few Evaluative-tags in the peer assessment Task 4 (Table 2) indicates that they were able 
to identify arguments in assigned articles but were less able to evaluate arguments in peer essays. The paucity of Evaluative-tags could have been due to several reasons. One may involve the significance of the task. Peer assessment was carried out at end of the unit after which there was no further evaluation on either reviewers or reviewees. Thus, students may not have been concerned about the quality of their work. Second, students might not have had a clear understanding about the meaning of the tags. We found that in Task 4 some students couldn't differentiate the meanings of Evaluative-tags. A third reason might have involved the peer relationship. As peer evaluations were not anonymous, students might have been unwilling to criticize the work of their peers. The question as to whether they were unable or simply unwilling to evaluate the arguments of peers calls for further investigation. However, more importantly, teachers should clarify both the purpose of the task and the use of the tags. This is in fact a common issue across the design of tasks and tools.

Students' writing skills with respect to argument structure and quality of reasoning were mediocre. Most didn’t even attempt to rebut arguments (Table 2). Argument structure skills were determined by the number and types of argument elements students included in their written arguments. The more elements they included, the more complex the argument structure. Most students were able to support claims with justifications and some even provided alternative perspectives with justifications. Although some students tried to rebut arguments, their rebuttals were weak or inadequate. Most students couldn't recognize the grounds of opposing opinions, much less undermine them. It might be even more difficult for them to recognize rebuttals of their own grounds so as to defend their arguments. The absence of rebuttals to arguments might have been due to a lack of emphasis by the teacher. An examination of the guidance that teachers provided students on writing arguments revealed that students were not clearly instructed to defend or rebut their claims. Thus, it is unclear whether students didn't try to rebut the arguments of peers because they couldn't or 
because no one had told them to. Kuhn (2010) suggested that when students received clear instruction on how to rebut arguments, they were able to do so. Further study should confirm this.

7.2 Why and how online reading activity affects the quality of arguments

Our goal in designing OASIS was to develop a set of tools for facilitating students' argumentation skills. Based on the assumption that the way in which students read arguments can affect the way in which they write arguments, we sought to facilitate their ability to read arguments by providing them with an argument framework to guide them. Students were provided with a set of reading tags designed by the teachers to help them understand arguments in teacher selected and self selected articles. Students were also provided with a set of evaluation tags to help them assess the written arguments of their peers. OASIS also provided a tool that students could use to generate their own tags while reading and evaluating written arguments. We hypothesized that by allowing students to create their own tags the tool would enable them to read written arguments with greater flexibility. Surprisingly, the number of My-tags that students generated while reading articles was the only significant factor affecting the quality of argument structure in their own written arguments while the number of teacher generated Task-tags was not significant. Our results indicated that students' argumentation skills were affected by their own efforts to understand what they were reading. Though carefully designed, the number of teacher generated Task-tags did not affect the quality of students' written arguments. The findings have the following implications: first, the effort of students to comprehend written arguments was the most important factor in accounting for improvements in their argumentation skills. It did not matter what kind of tagging students engaged in. It didn't even matter whether the tags were precise or not. What mattered were the cognitive processes such as thinking (of an 
appropriate tag), comparing (different tags), and reflecting (on why teacher's tags were not appropriate). These processes seemed to push students to form better understandings of the written arguments which in turn led them to write better quality arguments. Evidenced for this claim comes from students' responses to the questions in the why they generated their own tags.

Second, although the number of Evidence-tags and Position-tags were significantly correlated with argument structure, they were not significant predictors of the quality of argument structure when controlled by previous LS exam scores. Evidence-tags and Position-tags were significantly correlated with LS exam performance. Students with better exam scores were more inclined to use Task-tags. However, My-tags were not correlated with LS exam performance, neither teacher assigned tagging behavior which suggested that such learning behavior represented cognitive ability that could not be measured by the exam.

We found that some student-designed My-tags duplicated some teacher-defined Task-tags. For example, such My-tags as, “example”, “supporting evidence” and “opposing evidence” duplicated the Task-tag "Evidence”. This finding can be used in the design of more effective argumentation scaffolds. Students might need better and clearer structured argument model to scaffold reading. Thus, while self-defined My-tags helped students write better arguments, teacher-defined Task-tags did not. This finding suggests that to model and scaffold student argumentation more effectively calls for a better understanding of the cognitive processes involved.

\section{Implications}

Technology can play an important role in fostering argumentation skills, such as by providing external representations to help students construct science arguments. In this study, technology (OASIS) supported argumentation modeling for reading does not help 
construction of a written argument. This could be because the LS topic concerned the humanities as opposed to the sciences; it could also be because reading arguments and writing arguments involve different cognitive processes. Reading an argument doesn’t simple involve labeling its different parts that could be easily integrated into the written arguments. It involves such advanced cognitive processes as analyzing, comparing, reflecting, summarizing, and integrating. Support for these processes should also be considered in the design of argumentation tools and tasks. Thus, in designing argumentation tasks and tools, we must seek to support the cognitive processes involved in both reading and writing arguments.

Evaluating arguments (Task 4) was originally designed to foster advanced critical argumentation skills in addition to the argumentation skills of recognizing and identifying arguments involved in reading Tasks 1 and 2. However, the fact that students failed to engage actively in this task, implies that in addition to scaffolding the exercise of evaluation skills by providing evaluation tags, teachers should provide examples of individual tag in order to give students a better idea of how to apply them. Further, rubrics and examples should be set up for peer assessment activities in order to reinforce evaluation skills even when students don't use OASIS. Obviously, it is more difficult to model how to evaluate arguments than it is to model how to read them, but it is necessary to do so if students are to learn not only how to write arguments but how to critically evaluate them.

Students are weak at providing rebuttals and should receive specific instructions as to what rebuttals are and how to formulate them. The literature (Kuhn, 2010) also indicates that students should be given written examples of arguments to rebut and how to rebut them. Examples should be provided as to how to rebut, quality of rebuttals, and purpose of rebuttals.

Though focused on reading and writing arguments online, this study also has implications for online reading in general. As internet and ICT are becoming important sources of 
information in learning, new literacy skills are required to exploit and use them to solve problems. Reading online actually asks for more skills than reading print materials. It is an active problem-based inquiry process which consists of multiple steps from 1) setting a goal, 2) searching for relevant information, 3) locating information, 4) reading and evaluating the information, 5) synthesizing the information, and 6) communicating the online information (Leu et al., 2011). Throughout our working with teachers and students, we have found that students lacked support and guidance for all of these procedures. Given the increasing time students spend online and consequent change of their learning and reading behavior, there is a pressing need for revisiting the design, delivery, and assessment in reading and writing and the relevant curriculum and public policies (Leu, et al., 2011).

Integrating technology and research design with intact classes calls for the consideration of objectives, pedagogical design, assessment and many other practical issues of the curriculum design. Researchers, teachers, and technology designers have invested a great amount of effort in collaborating to bring about innovative changes in the class through technology. Due to limited exposure to OASIS, it is difficult to judge whether or not the students improved their writing skills over time. However, connecting the reading and writing arguments should direct teachers and students to develop and integrate such reading practices into regular teaching and learning activities. 


\section{Reference}

Andriessen, J. (2009). Argumentation in higher education: Examples of actual practices with argumentation tools. In N. M. Mirza \& A.-N. Perret-Clermont (Eds.), Argumentation and education: Theoretical foundations and practices (pp. 195-213). Dordrecht: Springer.

Andriessen, J. E. B., \& Schwarz, B. B. (2009). Argumentative Design. In N. Muller Mirza \& A.-N. Perret-Clermont (Eds.), Argumentation and Education (pp. 145-174): Springer US.

Bell, P. (2000). Scientific arguments as learning artifacts: designing for learning from the web with KIE. International Journal of Science Education, 22(8), 797 - 817.

Chang, S.-N., \& Chiu, M.-H. (2008). Lakatos' scientific research programmes as a framework for analysing informal argumentation about socio-scientific issues. International Journal of Science Education, 30(13), 1753-1773.

Chinn, C. A., \& Anderson, R. C. (1998). The structure of discussions that promote reasoning. Teachers College Record, 100(2), 315-368.

Chinn, C. A., O'Donnell, A. M., \& Jinks, T. S. (2000). The structure of discourse in collaborative leraning. The Journal of Experimental Education, 69(1), 77-97.

Clark, D., Sampson, V., Weinberger, A., \& Erkens, G. (2007). Analytic frameworks for assessing dialogic argumentation in online learning Environments. Educational Psychology Review, 19(3), 343-374.

Clark, D. B., Stegmann, K., Weinberger, A., Menekse, M., \& Erkens, G. (2007). Technology-Enhanced Learning Environments to Support Students' Argumentation. In S. Erduran \& M. P. Jiménez-Aleixandre (Eds.), Argumentation in Science Education (Vol. 35, pp. 217-243): Springer Netherlands.

Education and Manpower Bureau. (2007). Background. Liberal Studies: Currlculum and Assessment Guide (Secondary 4-6). Hong Kong.

Erduran, S. (2007). Methodological foundations in the study of argumentation in science classrooms. In S.

Erduran \& M. P. Jiménez-Aleixandre (Eds.), Argumentation in Science Education (Vol. 35, pp. 47-69): Springer Netherlands.

Erduran, S., Simon, S., \& Osborne, J. (2004). TAPping into argumentation: Developments in the application of Toulmin's Argument Pattern for studying science discourse. Science Education, 88(6), 915-933.

Friedman, R. S., \& Deek, F. P. (2002). Problem-based learning and problem-solving tools: Synthesis and direction for distributed education environments. Journal of Interactive Learning Research, 13(3), 239-257.

Garcia-Mila, M., \& Andersen, C. (2007). Cognitive foundations of learning argumentation. In S. Erduran \& M. P. Jiménez-Aleixandre (Eds.), Argumentation in Science Education (Vol. 35, pp. 29-45): Springer Netherlands.

Glover, I., Xu, Z., \& Hardaker, G. (2007). Online annotation - Research and practices. Computers \& Education, 49(4), 1308-1320. 
Goldstein, M., Crowell, A., \& Kuhn, D. (2009). What constitutes skilled argumentation and how does it develop? [argument; argumentation; development; metacognition; causal reasoning]. Informal Logic, 29(4), 379-395.

Hong Kong Exxamination and Assessment Authority. (2012). 2012 Hong Kong Diploma of Secondary Education (HKDSE) Examination_Liberal Study_Analysis on Candidates’ Performance. $\quad$ http://www.hkeaa.edu.hk/DocLibrary/Media/PR/Abstract_2012HKDSE_ERQP.pdf

Kelly, G. J., Regev, J., \& Prothero, W. (2007). Analysis of lines of reasoning in written argumentation. In S. Erduran \& M. P. Jiménez-Aleixandre (Eds.), Argumentation in Science Education (Vol. 35, pp. 137-158): Springer Netherlands.

Knudson, R. E. (1991). Effects of instructional strategies, grade,and sex on students' persuasive writing. Journal of Experimental Education, 59(2), 141-152.

Kobbe, L., Weinberger, A., Dillenbourg, P., Harrer, A., Hämäläinen, R., Häkkinen, P., et al. (2007). Specifying computer-supported collaboration scripts. International Journal of Computer-Supported Collaborative Learning, 2(2-3), 211-224. doi: 10.1007/s11412-007-9014-4

Kuhn, D. (1991). The skills of argument. Cambridge: Cambridge University Press.

Kuhn, D. (2005). Education for thinking. Cambridge, Massachusetts: Harvard University Press.

Kuhn, D. (2010). Teaching and learning science as argument. Science Education, 94(5), 810-824. doi: 10.1002/sce.20395

Kuhn, D., \& Goh, W. (2005). Arguing on the computer. Paper presented at the Computer-supported collaborative learning, Taipei.

Larson, A. A., Britt, M. A., \& Kurby, C. A. (2009). Improving students' evaluation of informal arguments. [Article]. Journal of Experimental Education, 77(4), 339-366.

Leu, D. J., Gregory McVerry, J., Ian O'Byrne, W., Kiili, C., Zawilinski, L., Everett-Cacopardo, H., et al. (2011). The New Literacies of Online Reading Comprehension: Expanding the Literacy and Learning Curriculum. Journal of Adolescent \& Adult Literacy, 55(1), 5-14. doi: 10.1598/jaal.55.1.1

Lu, J., \& Deng, L. (2012). Reading actively online: An exploratory investigation of online annotation tools for inquiry learning. Canadian Journal of Learning and Technology, 38(3), 1-16.

Means, M. L., \& Voss, J. F. (1996). Who reasons well? Two studies of informal reasoning among children of different grade, ability, and knowledge levels. Cognition and Instruction, 14(2), 139-178. doi: 10.1207/s1532690xci1402_1

Mercer, N. (2009). Developing argumentation: Lessons learned in the primary school. In N. Muller Mirza \& A.-N. Perret-Clermont (Eds.), Argumentation and Education (pp. 177-194). New York, NY: Springer. Muller Mirza, N., \& Perret-Clermont, A.-N. (2009). Introduction. In N. Muller Mirza \& A.-N. Perret-Clermont (Eds.), Argumentation and Education (pp. 1-5). New York, NY: Springer.

Muller Mirza, N., Perret-Clermont, A. N., Tartas, V., \& Iannaccone, A. (2009). Psychosocial processes in argumentation. In N. Muller Mirza \& A.-N. Perret-Clermont (Eds.), Argumentation and Education (pp. 67-90). New York, NY: Springer 
National Assessment of Educational Progress. (1998). NAEP 1998 Writing Report Card: Findings from the National Assessment of Educational Progress. Princeton, NJ: Educational Testing Service.

National Science Board. (2006). America’s pressing challenge-building a stronger foundation. Retrieved Sept. 20, 2010 http://www.nsf.gov/statistics/nsb0602/nsb0602.pdf

Neuwirth, C. M., \& Wojahn, P. G. (1996). Learning to write: Computer support for a cooperative process. In T. Koschmann (Ed.), CSCL: Theory and practice of an emerging paradigm Computers, cognition, and work (pp. 147-170). Mahwah, NJ: Lawrence Erlbaum Associates.

Nokelainen, P., Miettinen, M., Kurhila, J., Floréen, P., \& Tirri, H. (2005). A shared document-based annotation tool to support learner-centred collaborative learning. British Journal of Educational Technology, 36(5), 757-770.

Nussbaum, E., Winsor, D., Aqui, Y., \& Poliquin, A. (2007). Putting the pieces together: Online argumentation vee diagrams enhance thinking during discussions. International Journal of Computer-Supported Collaborative Learning, 2(4), 479-500.

Nussbaum, E. M., \& Sinatra, G. M. (2003). Argument and conceptual engagement. Contemporary Educational Psychology, 28, 384-395.

Oaksford, M., Chater, N., \& Hahn, U. (2008). Human reasoning and argumentation: The probabilistic approach. In J. Adler \& L. Rips (Eds.), Reasoning: Studies of human inference and its foundations (pp. pp. 383-413). New York: Cambridge University Press.

Osborne, J., Erduran, S., \& Simon, S. (2004). Enhancing the quality of argumentation in school science. Journal of Research in Science Teaching, 41(10), 994-1020.

Rau, P. L., Chen, S. H., \& Chin, Y. T. (2004). Developing web annotation tools for learners and instructors. Interacting with Computers, 16(2), 163-181.

Sadler, T. D., \& Fowler, S. R. (2006). A threshold model of content knowledge transfer for socioscientific argumentation. Science Education, 90(6), 986-1004.

Scardamalia, M. (2004). CSILE/Knowledge Forum. In A. Kovalchick \& K. Dawson (Eds.), Education and technology: An encyclopedia (pp. 183-192). Santa Barbara, CA: ABX-CLIO Inc.

Schwarz, B. B., Neuman, Y., Gil, J., \& Ilya, M. (2003). Construction of collective and individual knowledge in argumentative activity. Journal of the Learning Sciences, 12(2), 219-256.

Stegmann, K., Weinberger, A., \& Fischer, F. (2007). Facilitating argumentative knowledge construction with computer-supported collaboration scripts. International Journal of Computer-Supported Collaborative Learning, 2(4), 1556-1615.

Suthers, D. (2003). Representational guidance for collaborative inquiry. In J. Andriessen, M. Baker \& D. Suthers (Eds.), Arguing to learn: Confronting cognitions in computer-supported collaborative learning environments (pp. 27-44). Dordrecht, the Netherlands: Kluwer.

Suthers, D., Connelly, J., Lesgold, A., Paolucci, M., Toth, E., Toth, J., et al. (2001). Representational and advisory guidance for students learning scientific inquiry. In K. D. Forbus \& P. J. Feltovich (Eds.), 
Smart machines in education: The coming revolution in educational technology. (pp. 7-36). Menlo Park, CA: AAAI/Mit Press.

Toth, E. E., Suthers, D. D., \& Lesgold, A. M. (2002). Mapping to know: The effects of representational guidance and reflective assessment on scientific inquiry. Science Education, 86(2), 264-286.

Toulmin, S. E. (1958). The use of argument. Cambridge: Cambridge University Press.

van Amelsvoort, M., Andriessen, J., \& Kanselaar, G. (2007). Representational tools in computer-supported collaborative argumentation-based learning: How dyads work with constructed and inspected argumentative diagrams. Journal of the Learning Sciences, 16(4), 485 - 521.

van Drie, J., van Boxtel, C., Jaspers, J., \& Kanselaar, G. (2005). Effects of representational guidance on domain specific reasoning in CSCL. Computers in Human Behavior, 21(4), 575.

Van Eemeren, F., \& Grootendorst, R. (1994). Argumentation theory. In J. Verscheren \& J. Blommaert (Eds.), Handbook of pragmatics (pp. 55-61). Amsterdam: John Benjamins.

Venville, G. J., \& Dawson, V. M. (2010). The impact of a classroom intervention on grade 10 students' argumentation skills, informal reasoning, and conceptual understanding of science. Journal of Research in Science Teaching, 47(8), 952-977. doi: 10.1002/tea.20358

Walton, D. N. (1996). Argumentation schemes for presumptive reasoning. Mahwah, NJ: Lawrence Erlbaum Associates.

Wolfe, J. L. (2002). Annotation technologies: A software and research review. Computers and Composition, 19(4), 471-497.

Yang, Y.-F. (2010). A reciprocal peer review system to support college students' writing. British Journal of Educational Technology, 42(4). doi: 10.1111/j.1467-8535.2010.01059.x 
Figure Captions

Fig. 1: Screenshot of using OASIS for reading 


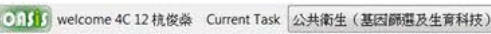

- Favorite Highlighter General Note Show

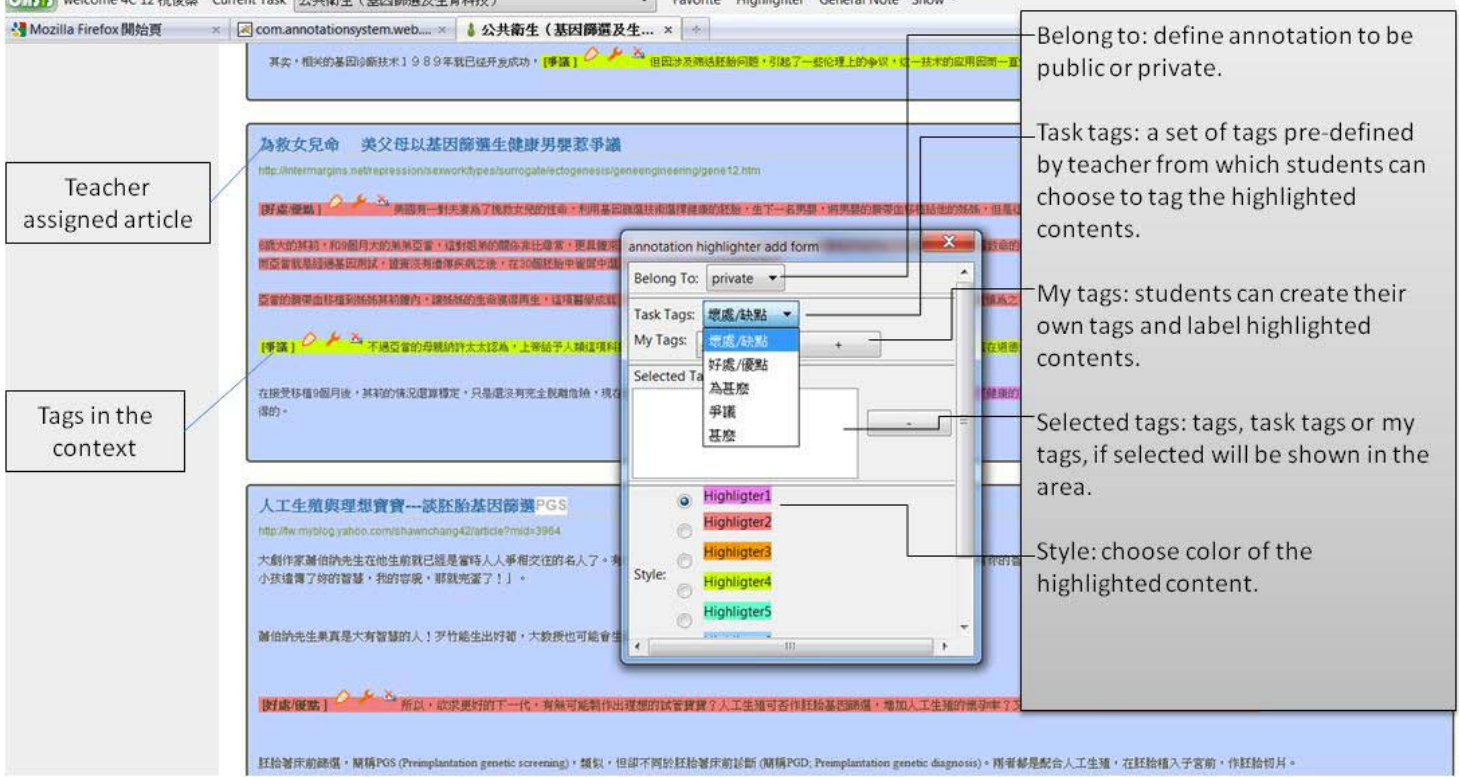


Table 1: Coding of argument structure

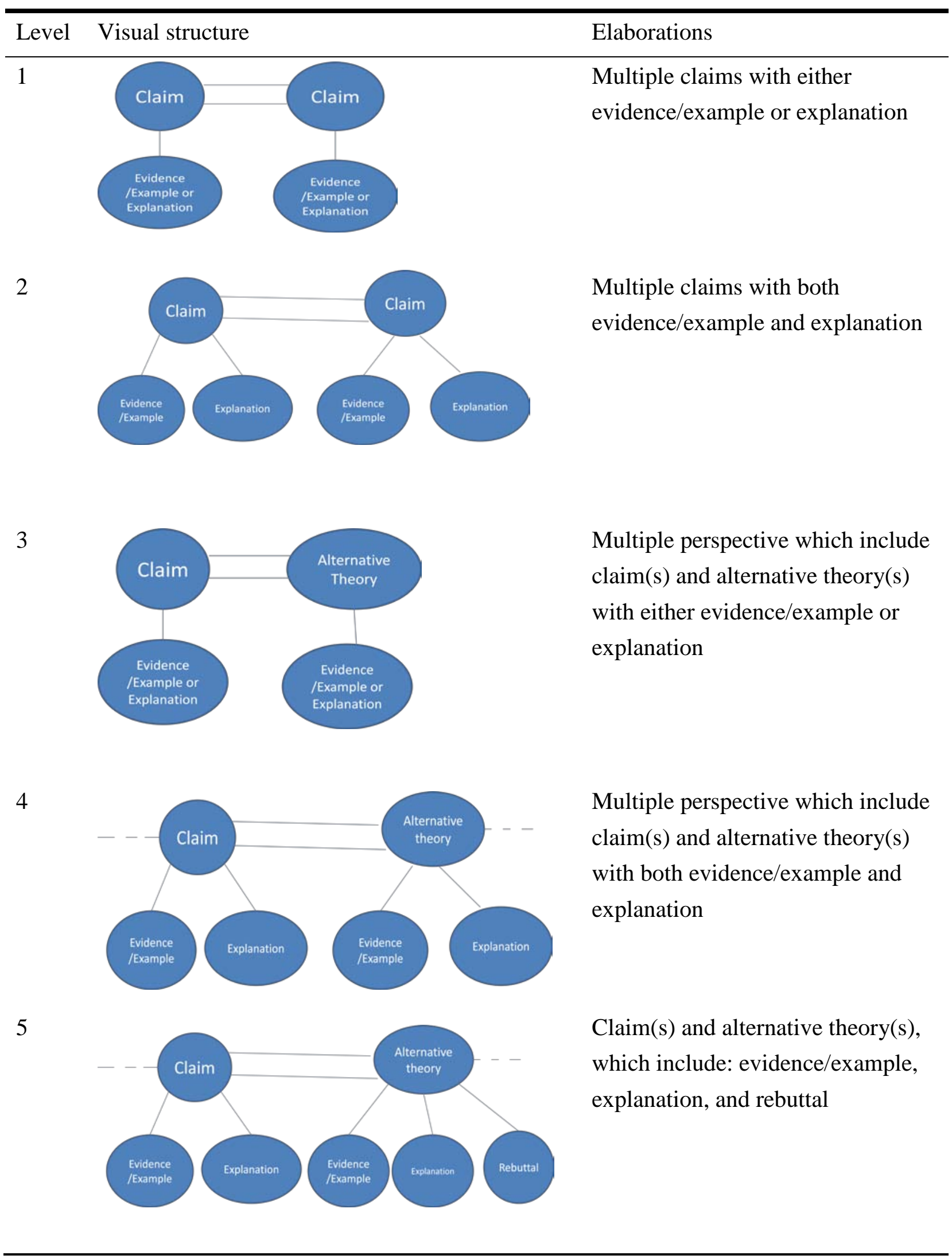


Table 2: Descriptive analysis of annotation activities and argument quality

\begin{tabular}{llllll}
\hline Variables & Mean & Min & Max & SD & N \\
\hline LS exam & 51 & 21.5 & 80 & 12.6 & 83 \\
Writing argument quality & & & & \\
$\quad$ Structure & 3.53 & 0 & 5 & 1.03 & 69 \\
$\quad$ Rebuttal & .58 & 0 & 3 & 1.09 & 69 \\
Task-tags in task 1 and 2 & & & & & \\
$\quad$ No. of Pros-tag & 5.86 & 0 & 10 & 3.82 & 79 \\
$\quad$ No. of Cons-tag & 6.03 & 0 & 20 & 4.51 & 79 \\
$\quad$ No. of Position-tag & 4 & 0 & 14 & 3.36 & 79 \\
$\quad$ No. of Argument-tag & 2.22 & 0 & 8 & 2.04 & 79 \\
$\quad$ No. of Evidence-tag & 7.16 & 0 & 31 & 6.01 & 79 \\
$\quad$ No. of My-tags & 2.99 & 0 & 37 & 6.51 & 79 \\
No. of Evaluating -tag in task 4 & 1.21 & 0 & 17 & 2.60 & 74 \\
No. of My-tags in task 4 & 1.22 & 0 & 17 & 2.60 & 74 \\
\hline
\end{tabular}


Table 3: Zero-order correlations among major variables

\begin{tabular}{|c|c|c|c|c|c|c|c|}
\hline & 1 & 2 & 3 & 4 & 5 & 6 & 7 \\
\hline 1. Structure & --- & & & & & & \\
\hline 2. LS exam & .22 & --- & & & & & \\
\hline 3. My-tags & $.28 *$ & .07 & --- & & & & \\
\hline 4. Position-tags & $.26^{*}$ & $.50 * *$ & .07 & --- & & & \\
\hline 5.Argument-tags & .031 & -.05 & .04 & .01 & --- & & \\
\hline 6.Evidence-tags & $.25^{*}$ & $.44 * *$ & .10 & $.45 * *$ & 0 & --- & \\
\hline 7. Pros \& Cons-tags & .11 & .12 & -.03 & $.22^{*}$ & .21 & $.35 * *$ & --- \\
\hline
\end{tabular}

Note: All the tags are the sum for task 1 and 2.

${ }^{*} \mathrm{p}<.05,{ }^{* *} \mathrm{p}<.01$ (two-tailed tests) 
Table 4: Hierarchical Multiple Regression Analysis in predicting argument structure $(\mathrm{N}=66)$

\begin{tabular}{llcccccc}
\hline & & $R^{2}$ & $R^{2}{ }_{\text {adj }}$ & $\Delta R^{2}$ & $F$ & $\beta$ & $t$ \\
\hline Step 1 & & .23 & .040 & .054 & 3.73 & & \\
& LS exam & & & & & .23 & 1.93 \\
Step 2 & & $.41^{*}$ & $.12^{*}$ & $.17^{*}$ & 3.20 & & \\
& & & & & & .12 & .89 \\
& LS exam & & & & .26 & 2.3 \\
& My-tag & & & & .14 & 1.07 \\
& Evidence-tag & & & & .15 & 1.11 \\
\hline
\end{tabular}

